\title{
Comorbidities and drug reactions in the elderly patient
}

\author{
Comorbidităţile şi reacţiile medicamentoase la pacientul vârstnic
}

\author{
Mihaela Adela lancu ${ }^{1,2}$, Laura Maria Condur ${ }^{2,3}$, Oana Nicolescu ${ }^{4}$, \\ Ana Maria Alexandra Stănescu ${ }^{1,2}$, Adriana Ticără $u^{1,2}$, Cristina Mihaela Olariu ${ }^{1,5}$, \\ Camelia Cristina Diaconu ${ }^{1,6}$, Dumitru Matei ${ }^{1,7}$ \\ ${ }^{1}$ Universitatea de Medicină şi Farmacie „Carol Davila“, Bucureşti, România \\ ${ }^{2}$ Cabinet medical individual, Bucureşti, România \\ ¿Universitatea „Ovidius", Constanţa, România \\ ${ }^{4}$ Direcţia de Sănătate Publică Bucureşti \\ IInstitutul Naţional de Boli Infecţioase „Prof. Dr. „Matei Balş“, Bucureşti, România \\ 'Spitalul Clinic de Urgenţă, Bucureşti, România \\ ${ }^{7}$ Institutul Naţional pentru Sănătatea Mamei şi Copilului „Alessandrescu-Rusescu“, Bucureşti, România
}

\begin{abstract}
Aging is characterized by progressive and broadly predictable changes that are associated with increased susceptibility to many diseases. The process of prescribing medication is complex and includes: deciding whether a drug is indicated, choosing the best drug, determining a dose and an appropriate schedule for the patient's physiologic status, monitoring the effectiveness and toxicity, educating the patient about expected side effects, and indications for seeking consultation. More than half of adults over the age of 65 consulted in primary care use at least 5 medications. The risk of drug interactions and side effects is increased by augmenting the number of drugs used, as well as pharmacokinetic and pharmacodynamic changes. Applying the Beers criteria to elderly patients decreases the risk of drug interactions and side effects.
\end{abstract}

Keywords: elderly, ageing, polipharmacy

\section{REZUMAT}

Procesul de îmbătrânire se caracterizează prin modificări progresive şi previzibile, care sunt asociate cu o susceptibilitate crescută la multe patologii. Procesul de prescriere a medicamentelor este complex şi include: prezenţa indicaţiei, alegerea celui mai bun medicament, aprecierea dozei şi ritmului de administrare adecvat pentru starea fiziologică a pacientului, monitorizarea eficacităţii şi toxicităţii, educarea pacientului despre efectele secundare preconizate şi indicaţii pentru a solicita consultul medical la apariţia efectelor secundare.Peste jumătate dintre adulţii peste 65 ani consultaţi în ambulator folosesc cel puţin 5 medicamente. Creşterea numărului de medicamente utilizate şi modificările farmacocinetice şi farmacodinamice sporesc riscul interacţiunilor medicamentoase şi al reacţiilor secundare. Aplicarea criteriilor Beers pacienţilor vârstnici scade riscul interacţiunilor medicamentoase şi al reacţiilor secundare.

Cuvinte cheie: vârstnic, îmbătrânire, polifarmacie

\section{IMPORTANȚA PROBLEMEI}

Patologia complexă a pacientului vârstnic, ce prezintă comorbidităţii multiple, este o situaţie frecvent întâlnită în practica medicului de familie şi crește determinismul plurivalent al managementului pacientului vîrstnic [1]. În ţările dezvoltate, aproximativ 1 din 4 adulţi are cel puţin două afecţiuni cronice [2], iar mai mult de jumătate dintre adulţii în vârstă au trei sau mai multe afecţiuni cronice [3]. Îmbunătăţirea mijloacelor de diagnostic precoce şi tratament a determinat scăderea mortalităţii la nivel global, determinând creşterea speranţei de viaţă. 
Conform ultimei definiţii OMS şi a Societăţii Americane de Geriatrie, se definesc următoarele perioade ale dezvoltării organismului uman în relaţie cu vârsta:

- Adultul tânăr 18(20)-40 ani

- Adultul matur 40-65 ani

- Adultul vârstnic > 65 ani

În cadrul ultimei etape de dezvoltare, se descriu următoarele subetape:

- Vârstnicul - young-old 65-75 ani

- Bătrânul - middle-old 76-85 ani

- Longevivul - old-old $>85$ ani [4].

\section{IATROGENIA LA VĂRSTNIC}

Riscul apariţiei iatrogeniei la vârstnic este strâns legat de anumiţi factori de risc precum polimedicaţia pacientului vărstnic, modificările farmacocinetice şi farmacodinamice ce au loc în această etapă de dezvoltare, numeroasele consulturi multidisciplinare ce determină prescrierea tratamentului farmacologic fără a avea în vedere necesitatea sintezei de diagnostic şi tratament individualizat pentru pacientul respectiv [3]. La toate aceste aspecte, se adaugă şi particularităţi individuale legate de nivelul educaţional şi socio-economic [3].

Analiza consumului de medicamente raportat la prescripţia lor ne arată un consum de medic la adulţi peste 65 de ani disproporţionat de mare chiar faţă de prescripţie [5]. Dacă populaţia peste 65 ani reprezintă aproximativ $13 \%$ din populaţia actuală a Statelor Unite ale Americii, se înregistrează un consum la aceşti pacienţi de aproximativ 33\% dintre medicamentele eliberate pe bază de prescripţie medicală [5]. Tot această categorie de populaţie reprezintă şi consumatorii pentru aproximativ $40 \%$ dintre medicamentele OTC comercializate [5]. Se estimează că, în SUA, pacienţii peste 65 ani diagnosticaţi şi trataţi în ambulatoriu au o schemă terapeutică ce cuprinde 2 până la 4 medicamente prescrise. Pacienţii instituţionalizaţi peste 65 de ani au o schemă terapeutică ce cuprinde 7-8 medicamente prescrise $[1,3,5]$. În general, se consideră că pacienţii peste 65 ani au o schemă terapeutică ce cuprinde peste 5 medicamente $[3,5]$.

Creşterea consumului de medicamente înregistrată în ultimii zece ani s-a făcut pe baza creşterii prescrierii de antihiperlipemiante, antidepresive, inhibitori de pompă de protoni, musculorelaxante $[1,5]$. Primele zece locuri ale prescripţiilor farmacologice sunt ocupate de: lisinopril, levotiroxin, metoprolol, metformin, hidroclorotiazidă, omeprazol, amlodipin, atorvastatin, albuterol [1,5].

\section{FACTORI CE CONTRIBUIE LA POLIPRAGMAZIE}

Polipragmazia este frecvent asociată cu vârsta pacientului peste 65 de ani din cauza prevalenţei şi/ sau severităţii afecţiunilor acestor pacienţi, în special cele cardiovasculare, metabolice şi oncologice [5].

În ultima perioadă, cercetările au îmbunătăţit extrem de mult tratamentul bolilor, crescând posibilităţile terapeutice, având la dispoziţie mai multe clase de medicamente din generaţii noi $[1,2]$.

Există un trend de a recomanda medicamente pentru a gestiona simptomele, fie de boală, fie de îmbătrânire, având drept scop creşterea calităţii vieţii [5].

De multe ori, în schema terapeutică găsim medicamente recomandate pentru tratarea efectelor secundare ale altor medicamente [5]. Consulturile multidisciplinare, prin mulţi medici prescriptori, determină o prescriere excesivă în raport cu un pacient, fără a avea în vedere necesitatea sintezei terapeutice $[1,5]$.

La toate aceste aspecte, se adaugă şi anumite particularităţi ale societăţii moderne, precum existenţa unui număr crescut de farmacii sau intensificrea publicităţii medicamentelor, a OTC, a suplimentelor alimentare $[1,3,5]$.

Un aspect important este reprezentat de faptul că pacienţii peste 65 ani au mai multe reacţii adverse la medicamente şi interacţiuni medicamentoase decât pacienţii mai tineri [5]. Aceste lucru apare şi ca urmare a unor deficienţe funcţionale multiple consecutive declinului fiziologic şi comorbidităţilor acestor pacienţi care afectează farmacocinetica şi farmacodinamia [5].

\section{CARACTERISTICILE PROCESULUI DE ÎMBĂTRÂNIRE}

Procesul de îmbătrânire se caracterizează prin modificări progresive şi previzibile, care sunt asociate cu o susceptibilitate crescută la multe patologii. Procesul de îmbătrânire nu este un proces omogen, nici în populaţia generală, dar nici la acelaşi individ. Se apreciază că organele şi sistemele aceleiaşi persoane suferă un proces de îmbătrânire cu intensitate variabilă şi la momente de timp diferite [6]. Procesul de îmbătrânire este influenţat de factori multipli, inclusiv terenul genetic, stilul de viaţă, dar şi de alţi numeroşi factori [5,6]. Modificările ADN epigenetice înregistrate în procesul de îmbătrânire sunt, de asemenea, specifice tipului de ţesut [7]. Cele mai importante aspect ale procesului de 
îmbătrânire sunt reprezentate de osteoporoză, sarcopenie, precum şi scăderea capacităţilor funcţionale cardiace, respiratorii, renale, hepatice, neurologice [6].

Scăderea capacităţilor adaptative la modificările ambientale în vederea menţinerii homeostaziei se numeşte homeostenoză [8].

Homeostenoza se caracterizează prin reducerea parametrilor fiziologici de răspuns sau bazali, reducerea răspunsului la stimuli externi, limitarea răspunsului maxim la stres, precum şi prin întărzierea momentului atingerii nivelului maxim de răspuns sau a revenirii ulterioare la statusul bazal $[6,8]$.

\section{MODIFICĂRI DE FARMACOCINETICĂ}

Modificările de farmacocinetică ce apar la pacienţii vârstnici interesează tulburări de absorbţie, distribuţie, de metabolism şi de excreţie [9].

Modificările care apar în procesul de absorbţie la pacienţii vârstnici sunt reprezentate de scăderea acidităţii gastrice, întărzierea în evacuarea gastrică, reducerea suprafeţei de absorbţie, precum şi reducerea motilităţii intestinale, scăderea fluxului sanguin intestinal $[8,9]$. Intestinul subţire suferă modificări anatomice, incluzând atrofia vilozităţilor intestinale şi îngroşarea mucoasei [10]. De remarcat faptul că absorbţia pasivă nu este afectată. Ca urmare a acestor modificări, are loc o scădere a absorbţiei fierului, calciului şi tiaminei la pacienţii vărstnici, ce determină o creştere a recomandărilor de utilizare a suplimentelor $[5,8]$. Absorbţia calciului din lumenul intestinal scade din cauza scăderii receptorilor de vitamina $\mathrm{D}$ din intestin şi a scăderii nivelului de circulaţie a vitaminei D (25)OH [10]. În absenţa leziunilor de tract gastro-intestinal, senescența nu reprezintă un factor care să afecteze semnificativ absorbţia, însă se înregistrează o creştere a biodisponibilităţii prin reducerea efectului primului pasaj hepatic $[8,9]$.

La pacienţii vărstnici, există modificări la nivelul distribuţiei medicamentelor în diferite ţesuturi. Aceste modificări se datorează reducerii sectorului hidric, reducerii masei slabe a organismului (fiind caracteristică apariţia obezităţii sarcopenice), precum şi variaţilor majore ale masei grase, prin denutriţie sau prin exces [8,9]. Astfel, se observă o creştere a volumului de distribuţie pentru acele substanţe liposolubile (de exemplu, lidocaina, diazepamul) şi o scădere a volumului de distribuţie pentru medicamentele hidrosolubile (de exemplu, digoxinul) [9]. Acest lucru impune ca schema terapeutică să fie modificată, apare necesitatea ajustării dozelor în funcţie de masa corporală. Chiar dacă procesul de denutriţie este frecvent după 70 ani şi este însoţit şi de scăderea sintezei albuminei şi a proteinelor de transport, capacitatea de legare a acestora nu este modificată [9]. Acest lucru impune acordarea unei atenţii desosebite la administrarea concomitentă a 2-3 medicamente ce pot concura pe acelaşi loc de fixare şi se pot înlocui reciproc.

Metabolismul medicamentelor şi al suplimentelor alimentare este influenţat de procesul de îmbătrânire. Masa hepatocitară scade între $20 \%$ şi $40 \%$ odată cu vârsta, iar perfuzia hepatică şi fluxul de sânge scad până la 50\% între a treia şi a zecea decadă de viaţă [11].

Declinul funcţiei hepatice, consecutiv reducerii debitului cardiac şi a masei hepatocitare, determină scăderea sintezei albuminei şi a proteinelor de transport, dar şi scăderea capacităţi de metabolizare pe cale hepatică a medicamentelor şi a eliminării hepatice (tabel 1).

TABEL 1. Medicamente/substanțe toxice al căror metabolism este influențat de vârstă

\begin{tabular}{|l|l|}
\hline Fără relație cu vârsta & Influențate de vârstă \\
\hline Alcool etilic & Propranolol \\
\hline Warfarină & Teofilină \\
\hline Izoniazidă & Tolbutamidă \\
\hline Lidocaină & Fenilbutazonă \\
\hline Prazosin & Barbiturice \\
\hline Nitrazepam & Alprazolam \\
\hline & Diazepam \\
\hline
\end{tabular}

Modificările de farmacocinetică înregistrate la nivelul etapei de excreţie sunt o consecinţă a procesului de îmbătrânire a ţesutului renal.

Masa renală scade cu 25-30\% la 80 de ani faţă de 30 de ani, cu declinul cel mai accentuat după vârsta de 50 de ani. De remarcat că la pacienţii vârstinici ţesutul adipos şi fibroza înlocuiesc o parte din parenchimul funcţional rămas. Pierderea apare în principal în cortexul renal şi afectează în mod preferenţial funcţia de concentrare a urinei [11]. Astfel, se constată o reducere a numărului de nefroni funcţionali şi reducerea fluxului sanguin renal cu aproximativ 53\%. Se înregistrează o scădere a filtrării glomerulare cu $1 \mathrm{ml} / \mathrm{min} / 1,73 \mathrm{~m} 2 / \mathrm{an}$, dar şi o scădere a secreţiei tubulare [11]. Scăderea masei musculare şi a producţiei de creatinină endogenă impun corecţia în calculul creatininemiei şi al clearance-ului creatininei pentru medicamentele cu excreţie renală recomandate (tabelul 2) $[12,13]$. De multe ori, prezenţa afecţiunilor asociate, precum adenomul de prostată, determină reevaluarea schemei terapeutice la aceşti pacienţi [13]. 
TABEL 2. Medicamente la care se impune ajustarea dozei la vârstnici, prin scăderea eliminării determinate de vârstă

\begin{tabular}{|l|}
\hline Medicamente la care se impune ajustarea dozei la vârstnici \\
\hline Aminoglicozide \\
\hline Atenolol \\
\hline Cimetidină \\
\hline Diazepam \\
\hline Digoxin \\
\hline AINS \\
\hline Hipoglicemiante \\
\hline Warfarină \\
\hline
\end{tabular}

Modificările farmococinetice se asociază cu modificări farmacodinamice. La pacienţii vârstnici, se modifică răspunsul la medicamente prin:

- Scăderea numărului de receptori betaadrenergici, dopaminergici

- Modificări de afinitate (conformaţionale) ale receptorilor - creşterea susceptibilităţii la hipnotice benzodiazepine

- Modificări morfologice şi functionale ale barierelor naturale - la nivelul barierei hematoencefalice determină creşterea susceptibilităţii la hipnotice

- Alterarea morfologică şi functională a a organului ţintă (de exemplu, la nivelul baroreceptorilor determină apariţia hipotensiunii arteriale ortostatice la administrarea de vasodilatatoare sau creşterea rezistenţei vasculare periferice determină scăderea răspunsului la vasodilatatoare, precum şi reducerea funcţiei de sinteză hepatică determină scăderea sintezei factorilor de coagulare, ceea ce impune recomandarea unor doze scăzute de warfarină) $[9,13,14]$.

La pacientul vârstnic, un aspect important al sintezei de tratament este reprezentată de diferenţa redusă între doza care determină eficienţa terapeutică şi doza la care se pot înregistra fenomene de supradozaj, din cauza procesului complex şi individualizat de îmbătrânire [15]. Acest lucru impune o atenţie deosebită la aceşti pacienţi care au o complianţă redusă la tratament, frecvent au recomandate scheme terapeutice complicate, prezintă tulburări de memorie de severitate diferită, dar au şi o posologie inadecvată, neadaptată la modificările survenite $[9,15]$.

Caracteristicile procesului de îmbătrânire determină o creştere a reacţiilor adverse la această categorie de pacienţi. De remarcat că $2-5 \%$ dintre internări se datorează apariţiei reacţiilor adverse, iar mortalitatea la pacienţii care au raportat recţii adverse variază de la 2\% la 12\% [9,16]. Probabilitatea apariţiei reacţiilor adverse creşte cu numărul de medicamente administrate; astfel, la 6 medicamente avem o probabilitate de apariţie a reacţţilor adverse de $5 \%$, iar la peste 15 medicamente avem o probabilitate de apariţie a reacţiilor adverse de $20 \%$ $[9,16]$.

Principalele tipuri de reacţii adverse întălnite la pacienţii vârstnici sunt reprezentate de

- Valori anormale ale parametrilor paraclinici - de exemplu, citoliză hepatică după administrarea de antibiotic

- Simptomatologie sau diferite semne evidenţiate la examenul clinic (afecţiuni dermatologice)

- Efecte adverse (de exemplu, administrarea antidepresivelor triciclice determină apariţia uscăciunii la nivelul mucoaselor)

- Toxicitate crescută, precum hipnoticele, care pot determina şi somnolenţă diurnă

- Interacţiuni medicamentoase - cu anumite afecţiuni (de exemplu, bezodiazepinele/anticolinergicele scad funcţia cognitivă la pacienţii cu boală Alzheimer)

- Interactiuni medicamentoase - digoxin-diuretic

- Efecte secundare - haloperidolul poate determina sindrom Parkinson [9,17].

Pentru a prescrie o schemă terapeutică la pacientul vârstnic, trebuie să răspundem mai întâi la căteva întrebări:

1. Este necesară terapia farmacologică? - avem în vedere includerea medicamentelor strict necesare tratamentului comorbidităţilor.

2. Ce tip de preparat trebuie ales? - şi trebuie să evaluăm dificultăţile de înghiţire, de vedere, cognitive.

3. Cum se ajustează doza? - evaluat individual fiecare pacient.

La evaluarea pacientului vârstnic în vederea recomandării schemei terapeutice, vom evalua următoarele situaţii:

- $\mathrm{Nu}$ există niciun medicament pentru a trata senescenţa

- Se exclud medicamentele ce scad calitatea vieţii

- Se face o analiză riguroasă a raportului eficacitate/riscuri

- Stabilirea unor priorităţi pentru tratament, mai ales pentru produsele nefarmacologice

- Recomandaţi numărul minim de medicamente administrate concomitent

- Aprecierea funcţiei hepatice, renale

- Iniţial, se recomandă doze mici, ce sunt crescute progresiv

- Anticiparea reacţiilor adverse 
- Educarea pacientului şi a familiei

- Reevaluarea permanentă

- Criteriile Beers - identificare medicamentelor considerate inadecvate atunci când sunt prescrise vârstnicilor $[9,18]$.

În anul 1991, un grup de experţi geriatri a elaborat criteriile Beers, actualizate în 2019. Au fost identificate medicamente cu risc crescut, aspect bazat pe riscul evenimentelor secundare şi pe consecinţele clinice ale acestora. De remarcat că prescrierea şi monitorizarea comorbidităţilor ar trebui individualizate. Aceste criterii subliniază, de asemenea, importanţa utilizării unei abordări multidis- ciplinare în ceea ce priveşte prescrierea medicamentelor la vârstnic [18].

\section{CONCLUZII}

Peste jumătate dintre adulţii peste 65 ani consultaţi în ambulator folosesc cel puţin 5 medicamente. Creşterea numărului de medicamente utilizate şi modificările farmacocinetice şi farmacodinamice sporesc riscul interacţiunilor medicamentoase şi al reacţiilor secundare. Aplicarea criteriilor Beers pacienţilor vârstnici scade riscul interacţiunilor medicamentoase şi al reacţiilor secundare.

Conflict of interest: none declared Financial support: none declared

12. Denic A, Lieske JC, Chakkera HA et al. The Substantial Loss of Nephrons in Healthy Human Kidneys with Aging. J Am Soc Nephrol. 2017;28:313.

13. Denic A, Mathew J, Lerman LO et al. Single-Nephron Glomerular Filtration Rate in Healthy Adults. N Engl J Med. 2017;376:2349.

14. Zhu Y, Armstrong JL, Tchkonia T, Kirkland JL. Cellular senescence and the senescent secretory phenotype in age-related chronic diseases. Curr Opin Clin Nutr Metab Care. 2014;17:324.

15. Meltzer-Brody S, Colquhoun H, Riesenberg R et al. Brexanolone Injection in Post-Partum Depression: Two Multicentre, Double-Blind, Randomised, Placebo-Controlled, Phase 3 Trials. Lancet. 2018;392(10152):1058-70.

16. Wood AJJ. Adverse Reactions to Drugs. In: Fauci SAS, Braunwald E, Kasper DL, Hauser SL, editors. Harrison's Principles of Internal Medicine. 15th ed. New York: McGraw Hill, 2001. pp. 430-438.

17. Alhawassi TM, Krass I, Bojouk BV, Pont LG. A Systematic Review of the Prevalence and Risk Factors for Adverse Drug Reactions in the Elderly in the Acute Care Setting. Clin Interv Aging. 2014;9:2079-86.

18. By the 2019 American Geriatrics Society Beers Criteria ${ }^{\circ}$ Update Expert Panel. American Geriatrics Society 2019 Updated AGS Beers Criteria ${ }^{\circledR}$ for Potentially Inappropriate Medication Use in Older Adults. J Am Geriatr Soc. 2019;67(4):674-694. 